\title{
criterios sobre normas
para cemento
}

J. CALleJA, Dr. en Ciencias Químicas

\section{ressumern}

Las diferentes normas nacionales para cemento definen y clasifican a los conglomerantes hidráulicos. Contienen especificaciones de carácter general y de naturaleza química, física y mecánica que deben cumplir los distintos tipos, clases y categorías o calidades de cemento. En cuanto al número y condición de las especificaciones, todas las normas suelen ser muy acordes y a la vez muy completas.

Sin embargo, una norma general no puede tener en cuenta toda la casuística de empleos y aplicaciones, a veces muy especificos, de los cementos. Por lo tanto, puede ser necesario o conveniente, en determinadas circunstancias, complementar de forma cualitativa y/o cuantitativa las normas de carácter general, con especificaciones más detalladas, e incluso con nuevas prescripciones para casos especiales. Estas prescripciones y detalles suelen tener cabida en normas de carácter, validez y campo de aplicación particulares, que en nuestro país suelen llamarse "Pliegos Especiales o Particulares de Condiciones" para un determinado tipo de obra o de utilización de los cementos.

En este trabajo se trata de desarrollar una serie de ideas, criterios y directrices que se considera deben orientar y presidir el establecimiento de especificaciones y prescripciones en eventuales pliegos especiales o particulares, cuando la necesidad de estos pliegos queda satisfactoriamente justificada.

Por ser múltiples los casos de empleos específicos o especiales de los cementos en general y de los cementos portland en particular, se consideran todos estos casos en conjunto $y$ de una manera general, sin particularizar concretamente en ninguno dado, pues esto último requeriría un tratamiento extenso y por separado de cada uno de ellos.

La exposición que se hace sigue el orden adoptado en la norma española para conglomerantes hidráulicos PCCH-64. 


\section{introducción}

\subsection{NORMAS DE CARACTER GENERAL}

Sabido es que en cada país existen normas con las que deben cumplir ciertos materiales y productos. Estas normas, que por lo común tienen un carácter general y se extienden por ello en un vasto campo de aplicación, incluyen una serie de especificaciones que contienen a su vez requisitos o prescripciones a los cuales obligatoriamente deben satisfacer los materiales afectados.

Tales prescripciones consisten usualmente en límites máximos o mínimos que no deben ser alcanzados o rebasados, intervalos dentro de los cuales deben encajar los valores numéricos correspondientes a los conceptos objeto de especificación, o condiciones, a veces expresables en forma de relación matemática, que deben cumplir determinados parámetros.

Aparte de estos requisitos de carácter cualitativo y/o cuantitativo, las normas incluyen los métodos de ensayo para determinar los correspondientes valores numéricos, en su caso.

Cuando un material puede presentarse en distintas variedades en cuanto a "tipo", "clase" o "categoría" ("calidad") —o en cuanto a cualesquiera otras modalidades emanadas de un criterio taxonómico-, las normas pueden prever diferentes especificaciones y prescripciones para cada variedad. En este caso, y a la reciproca, el cumplimiento de unas u otras de tales especificaciones y prescripciones sirve para definir $\mathrm{y}$, por lo tanto, para clasificar el material en cuestión.

En lo que se refiere concretamente a cemento, existen normas nacionales de los distintos países, entre las que destacan por su difusión y utilización las normas norteamericanas ASTM, (1), las alemanas DIN, (2), las inglesas BSS, (3), y las soviéticas GOST, (4). Una recopilación útil de todas ellas, con carácter internacional, se da en las publicaciones del CEMBUREAU, (5), relativas a cementos portland, (6), y no portland, (7).

En cuanto a organismos internacionales que en un aspecto u otro se ocupan de problemas de normalización, $\mathrm{y}$ en particular de los concernientes a cemento, aparte del citado CEMBUREAU cabe mencionar la ISO, (8), y la RILEM, (9). Algunos de estos organismos, aislada o conjuntamente, han elaborado y difundido métodos de ensayo que han sido adoptados por diversos países, en unión con, o en sustitución de los propios métodos nacionales. Tal es el caso del método de ensayo de cementos "RILEM-CEMBUREAU".

La norma nacional española para cemento es el "Pliego General de Condiciones para la Recepción de Conglomerantes Hidráulicos en las Obras de Carácter Oficial", cuya versión más moderna y vigente hoy es el PCCH-64, (10), aprobado por Orden Ministerial del 9 de abril de 1964, publicada en el Boletín Oficial del Estado número 109, del 6 de mayo del mismo año, y con las correcciones aparecidas en el Boletín Oficial del Estado número 222, del 15 de septiembre de 1964. EI PCCH-64 ha adoptado el método RILEM-CEMBUREAU en lo que respecta a los ensayos mecánicos de los cementos.

Los organismos nacionales que de una forma u otra suelen intervenir en la normalización en general, y/o en la relativa a cementos en particular, figuran el Instituto de Racionalización y Normalización, (11), el Instituto "Eduardo Torroja" de la Cons- 
trucción y del Cemento, el Laboratorio Central para el Ensayo de Materiales de Construcción, del Centro de Investigación de Obras Públicas, el Laboratorio "EXCO" del Ministerio de la Vivienda, el Laboratorio de Ingenieros del Ejército, la Agrupación de Fabricantes de Cemento, las Direcciones Generales y las Secretarias Técnicas de los Ministerios implicados en el tema (Obras Públicas, Vivienda, Industria, Ejército), etcétera. Esto demuestra el múltiple interés que tiene la normalización del cemento como producto clave de dos industrias básicas: la de la propia fabricación del cemento y la de la construcción.

Este interés se ha reflejado de una forma patente en el hecho de que el tema relativo a "Pliegos de Condiciones" ha estado presente en todos los Coloquios de Directores y Técnicos de Fábricas de Cemento celebrados bajo los auspicios y la organización del Instituto "Eduardo Torroja", y que hasta la fecha han sido cuatro: (12), (13), (14) y (15). El autor de este trabajo, como Coordinador y Ponente General de! último de los citados Coloquios, ha expuesto en la Memoria relativa al mismo un comentario, (16), acerca del problema de los Pliegos de Condiciones. Como aclaración del comentario de entonces puede añadirse ahora que en la elaboración de una norma deben cooperar todas las partes interesadas en la misma, tanto del campo científico como del técnico en sus aspectos de fabricación y utilización del producto, como del económico; y al decir "partes" se quiere significar organismos y personas. Sólo así se puede llegar a la primera a un resultado completo, satisfactorio y justificable en todos los aspectos citados.

\subsection{NORMAS DE CARACTER PARTICULAR}

Aparte de las normas generales que debe cumplir un determinado producto o material existen, o pueden existir a veces, otras normas de carácter particular a las que debe satisfacer también aquél: Estas normas particulares deben ser complemento de las generales.

Las normas de carácter particular tienen su razón de ser en atención a las diversas condiciones de empleo y a las finalidades específicas para las que se utilice el producto o material en cada caso. En realidad, la necesidad de normas particulares, cuando realmente se da, puede considerarse como un índice de insuficiencia de las normas generales, al menos en los casos concretos en los que tal suceda. En efecto, si estas normas generales incluyesen cualitativa y/o cuantitativamente todos, o los más de los aspectos a considerar en el material, teniendo en cuenta todas, o la mayoria de las circunstancias y finalidades de su uso, ello permitiría la clasificación del material en una amplia gama de variedades en la que podría tener encaje cualquier tipo de aplicación práctica de aquél. En resumen, se dispondría, en el caso ideal más completamente resuelto, de un tipo o clase del material como más idóneo para cada finalidad. Esto, naturalmente, puede parecer utópico, pero, por conveniente, se debería tender a ello, como ya lo han hecho determinadas normas nacionales de prestigio internacional.

En lo que atañe en particular a cemento, hay empleos específicos de este material que pueden requerir características especiales. Así, por ejemplo, la prefabricación de elementos constructivos, la construcción de firmes de hormigón, o de obras hidráulicas, o la construcción en el mar, o en medios y ambientes agresivos, etc. Una norma general completa, por el hecho de serlo, resuelve de modo satisfactorio prácticamente la totaiidad de los casos específicos que puedan presentarse. Las soluciones, se- 
gún las circunstancias, pueden consistir, o bien en el empleo de distintos tipos de cemento, o bien en el uso de determinadas clases y/o categorías dentro de un mismo tipo *.

En este orden de ideas, y por vía de ejemplo, las normas ASTM resolverían la prefabricación con cemento portland tipo III; los firmes de hormigón con cemento portland tipo I; las presas con cemento portland tipo II o tipo IV, o con cemento puzolénico; las obras en el mar con cemento portland tipo $\mathrm{V}$, o con cemento puzolánico, o con cemento siderúrgico; las cimentaciones en terrenos yesíferos con cemento portland tipo $\mathrm{V}$, o con cemento siderúrgico, o con cemento puzolánico. La solución en cada caso no tiene por qué ser única, sino que puede ser múltiple, y la elección de una u otra alternativa podrá depender entonces de circunstancias que deben ponderar con buen juicio los técnicos responsables de la obra.

Como se ve, no es precisa de forma imprescindible la existencia de normas particulares cuando la norma general es completa, pues basta en la mayoría de los casos con el conocimiento de las características principales de cada tipo, clase y categoría de cemento, y con saber elegir las más determinantes de dichas características para el caso de que se trate. Algo análogo a lo indicado respecto de las normas ASTM en los ejemplos anteriores podría decirse también respecto de la mayor parte de las normas nacionales.

En cuanto a las normas españolas, el PCCH-61 también ofrece soluciones en los distintos casos antes planteados. Así, por ejemplo. la prefabricación se resolvería con cemento portland P-450; los firmes de ho migón con cementos portland P-250 ó P-350; las presas con cementos portland o puzolánicos de bajo calor de hidratación; las obras marítimas con cementos puzolánicos, o siderúrgicos, o portland PAS; las cimentaciones en suelos yesíferos con cementos portland PAS, o siderúrgicos, o puzolánicos.

En el caso de las normas españolas tampoco parece imprescindible, en principio y en general, un "Pliego Particular de Condiciones" para cada uno de los empleos específicos de los cementos antes señalados, y eventualmente para otros que pudieran señalarse, máxime cuando existen publicaciones, complementarias en cierto modo del Pliego General, en las que se hace - y se justifica-- una serie de recomendaciones relativas al empleo de los distintos tipos, clases y calidades de los conglomerantes incluidos en el citado Pliego, (17), (18), (19) y (20). Indicaciones del mismo o de análogo tipo constan también en las "Instrucciones" para los diversos tipos de materiales y obras, (21), (22) y (23).

\subsubsection{Condiciones que debe reunir una norma o "pliego" de carácter particular.}

Cuando, a pesar de lo anteriormente expuesto, se juzgue imprescindible implantar una norma de carácter particular, es bien evidente que las prescripciones que ésta incluya deben ajustarse, imprescindiblemente también, a una serie de condiciones. Entre éstas; por elementales y evidentes que parezcan, conviene recordar las siguientes:

: las nuevas prescripciones deben responder justificadamente a una necesidad o finalidad no prevista o no resuelta en la norma general correspondiente;

" "Tipo", "clase" y "categoría" ("calidad") se emplean con el mismo sentido que tienen en el PCCH-64. 
1. las nuevas prescripciones no pueden estar, total o parcialmente, en pugna con las de la norma general;

- las nuevas prescripciones deben ser de cumplimiento posible, y, en la mayor medida que sea dado, de forma técnicamente fácil y económica para las partes implicadas;

2. las nuevas prescripciones deben ser el resultado de una experiencia -o de una experimentación- que responda lo más y mejor posible a la realidad práctica que se haya de afrontar y resolver con dichas prescripciones; etc.

Todas y cada una de estas condiciones se tuvieron presentes por parte del autor en el comentario a que antes se ha aludido, (16), cuando en dicho comentario se recomendaba para posibles pliegos especiales o particulares “... prudencia en las exigencias $\mathrm{y}$, sobre todo, que éstas tengan una plena y absoluta justificación, técnica y objetiva, que convenza sin reservas a todas las partes interesadas".

En este trabajo se trata, en virtud de todo lo que antecede, de analizar objetivamente los casos y circunstancias en que, según los empleos y aplicaciones del cemento portland, serían precisas nuevas prescripciones no previstas, total o parcialmente, en la norma española PCCH-64; así como también de determinar en qué forma y medida podrían y deberian establecerse las correspondientes precisiones.

\section{prescripciones de las normas para cemento}

\subsection{PRESCRIPCIONES DE TIPO FISICO-MECANICO.}

Se refieren éstas en el PCCH-64 a la finura de molido (residuo sobre tamices o, alternativamente, superficie específica según Blaine), al peso especifico real mínimo, al principio y al fin del fraguado, a la estabilidad de volumen (expansión en autoclave) y a las resistencias mecánicas a flexotracción y a compresión.

De estas prescripciones, las dos primeras no se comentan en el caso presente, $\mathbf{y}$ basta con que se cumplan, sin que parezca pr scedente hacer precisiones mayores respecto de ellas en circunstanciales pliegos particulares, a menos que de algún modo se desee limitar la retracción --véase 2.6.1一, en cuyo caso cabria pensar en poner un tope a la superficie específica Blaine, particularmente en el caso de los cementos puzolánicos.

El tiempo de fraguado, en cambio, puede oscilar entre limites tan amplios, tanto por lo que se refiere al principio como al final del mismo, que podría estar justificado en algún caso particular precisar más o estrechar dichos límites, en el sentido de retrasar el principio o adelantar el final. Por ejemplo, en los cementos para inyecciones, o para pozos petroliferos, suele convenir que el fraguado sea particularmente lento, sobre todo por lo que hace al comienzo del mismo.

La estabilidad de volumen determinada por el ensayo de autoclave es un punto del que por circunstancias particulares habrá que tratar con mayor amplitud y detalle en otra ocasión y lugar, (24), - véase también 2.3.6-.

Las resistencias mecánicas constituyen uno de los puntos en que las normas en general y el PiCCH-64 en particular son más precisos, y la posible elección de una u otra de las categorías o calidades dentro de cada tipo o clase de cemento parece hacer innecesaria cualquier especificación complementaria al respecto. A tal elección deben 
ayudar las "Recomendaciones", las "Instrucciones" de carácter general, e incluso los "Pliegos Particulares o Especiales", pero siempre dentro del marco del PCCH-64. Pueden, sin embargo, implantarse prescripciones adicionales en un eventual pliego particular o especial, en el sentido de exigir para las resistencias valores determinados a edades para las que el PCCH-64 no fija valor alguno; o en el sentido de exigir resistencias en hormigón, aparte de las resistencias en mortero normal; o con la intención de exigir que las resistencias en mortero normal se obtengan como medias de un número de probetas prefijado, y mayor que el mínimo previsto en el PCCH-64, a fin de reducir el error probable de la media obtenida, (25).

En las "Instrucciones" y en los "Pliegos Particulares" se suelen definir determinadas "resistencias medias" o "resistencias caracteristicas", etc., con las cuales se opera, (21) y (22). Cabe hacer una observación en cuanto al número y condición de los valores considerados o conservados para el cálculo de la verdadera resistencia media. Por principio, todos los valores experimentales de una serie de roturas deben utilizarse en dicho cálculo, sin desestimar ninguno, a menos que se tenga evidencia de que los que se eliminan están afectados de un error imputable a una causa perfectamente conocida. Pero si uno o varios resultados parecen anormales sin que resulte posible establecer la causa de la presunta anormalidad, no hay razón para eliminarlos "a priori". Sólo serán eliminables si el correspondiente cálculo estadístico los declara "resultados aberrantes", en función del valor medio, de la desviación standard y del intervalo de confianza para una probabilidad elegida que suele ser la de 95 por ciento, (25).

Así, pues, los distintos criterios arbitrarios que a veces se trata de imponer, tales como el de suprimir un determinado tanto por ciento de los valores más altos $\mathrm{y} / \mathrm{o}$ de los más bajos, o como el de suprimir todos los valores que se desvíen de la media en más o en menos un determinado tanto por ciento, por su misma arbitrariedad carecen de justificación. Se entiende que en el cálculo de una media hay que incluir todos los valores que deban intervenir en dicho cálculo, salvo que la "media" deje de serlo en absoluto. Otra cosa es que, al margen de dicho cálculo hecho con toda corrección, por razones de seguridad, garantía, confianza, etc., la media se modifique "a posteriori" con un coeficiente de reducción o con un criterio que responda a los principios que sean del caso. También es distinto - -y correcto- exigir mayor número de probetas para obtener una media afectada de un error probable menor, como se indicaba anteriormente.

Los citados criterios arbitrarios podrian enfrentarse muchas veces con algunas de las condiciones señaladas en 1.2.1, y en particular con la b), pues podrían no coincidir con la "interpretación, valoración y expresión de los resultados" dadas por el correspondiente método de ensayo de la norma general o de eventuales "normas de calidad" complementarias de aquélla.

En todo caso, lo que sí se puede y se debe conocer es el error probable sobre la media de resultados de un método de ensayo, determinándolo si es preciso. Y tanto más cuanto que dicho error depende de los laboratorios (equipos, materiales y operadores) y puede ser sustancialmente distinto de uno a otro.

\subsection{PRESCRIPCIONES DE TIPO QUIMICO}

Destaca el hecho de que las prescripciones de tipo químico esporádicamente suelen ser objeto de concentrada atención por parte de algunos técnicos, hasta el punto 
de considerar a veces insuficientes para ciertas aplicaciones del cemento, no sólo las prescripciones generales del PCCH-64, sino incluso las especiales relativas a conglomerantes de características muy particulares. En lo que sigue se glosa la mayor parte de estas prescripciones, siguiendo el orden en que aparecen en el correspondiente cuadro y texto del PCCH-64.

\subsubsection{Limitación del óxido magnésico.}

La limitación del óxido magnésico responde fundamentalmente al hecho de que este componente "menor" del cemento portland se encuentra libre, como tal óxido, sin formar constituyentes hidráulicos, y puede producir expansiones a largo plazo si se hidrata a partir de su forma cristalizada, la "periclasa". En cambio, no parece causar tales expansiones cuando se encuentra en forma vítrea. La presencia de la "magnesia" en una u otra forma en el cemento portland está determinada por el curso del enfriamiento del "clínker" durante el proceso de su fabricación.

De esto se deduce que, más que la cantidad de magnesia en el cemento portland es el estado en que la magnesia se encuentra en el mismo lo que condiciona que el cemento sea o no expansivo por tal concepto. El objeto principal del ensayo de autoclave ASTM, (26), es precisamente forzar la hidratación de la magnesia para poner de manifiesto si se produce o no expansión y, en caso de producirse, en qué medida tiene lugar ésta. En confirmación de lo anterior, resultados de ensayos de autoclave han revelado que cementos con menor contenido de magnesia total que otros eran expansivos, mientras que estos otros no lo eran, ya que en los primeros la proporción de periclasa era mucho mayor que en los segundos.

Quiere decir esto que, si la limitación del contenido de óxido magnésico responde sólo a evitar la posibilidad de expansión, dicha limitación es superflua para todos los cementos (excepto para los SF-250: siderúrgicos sobresulfatados), tanto por lo expuesto como porque el ensayo de autoclave es preceptivo para todos ellos (salvo los mencionados SF-250) en el PCCH-64 - véase 2.3.6--. Por lo tanto, nada habría que forzar en cuanto al óxido magnésico del cemento, con vistas a cualquier pliego particular de condiciones. Este aserto queda avalado por los siguientes hechos: los contenidos de magnesia tolerados para todos los tipos de cemento portland en todas las normas reseñadas por el CEMBBUREAU oscilan entre un máximo de $6 \%$ y un mínimo de $2,5 \%$, con un valor medio de 4,6\%. Por Io tanto, la limitación española coincide prácticamente con la media mundial. Esta ha sido calculada sobre un total del orden de setenta y cinco valores, cuarenta y cinco de los cuales son iguales a $5 \%$, dos superiores a $5 \%$ y el resto, veintiocho, inferiores a 5 por ciento.

\subsubsection{Limitación del trióxido de azufre.}

Respecto de esta limitación se ha tratado tanto en otros aspectos, y precisamente por parte del autor, que basta hacer mención aquí de los trabajos y publicaciones correspondientes acerca del tema, (27), (28), (29), (30) y (31). En resumen, no es limitación que deba ser objeto de modificaciones en ningún pliego particular eventual.

\subsubsection{Limitaciones de la pérdida al fuego y del residuo insoluble.}

Por razones obvias se tratan ambas simultáneamente, (32), (33) y (34). 
La pérdida al fuego máxima tolerada por el PCCH-64 para todos los cementos portland y siderúrgicos es de $4 \%$. Las pérdidas al fuego toleradas para todos los tipos de cemento portland en todos los países cuyas normas reseña el CEMBUREAU oscilan en tre un máximo de $5 \%$ (eventualmente $7 \%$ ) y un mínimo del $1 \%$, con un valor medio de $3,7 \%$ (prácticamente $4 \%$ ). Por lo tanto, la limitación española coincide con la media mundial. Esta ha sido calculada sobre un total del orden de sesenta y cinco valores, dieciséis de los cuales son iguales a $4 \%$, otros dieciséis superiores a $4 \%$ y el resto, treinta y tres, inferiores a $4 \%$. Es interesante señalar que una de las normas que tolera una pérdida al fuego de $4 \%$ eleva esta tolerancia hasta el $5 \%$ cuando la muestra de cemento procede de la obra.

El residuo insoluble máximo tolerado por el $\mathrm{PCCH}-64$ para todos los cementos portland y siderúrgicos es de $3 \%$. Los residuos insolubles tolerados para todos los tipos de cemento portland en todos los países cuyas normas reseña el CEMBUREAU oscilan entre un máximo de $5 \%$ (eventualmente $6 \%$ ) y un mínimo de $0,7 \%$, con un valor medio de $1,5 \%$. Por lo tanto, la limitación española es del orden del doble de la media mundial. Esta ha sido calculada de setenta y cinco valores, cuatro de los cuales son iguales a $3 \%$, cinco superiores a $3 \%$ y el resto, sesenta y seis, inferiores a 3 por ciento.

A la vista de esto cabe deducir que la pérdida al fuego puede muy bien no ser objeto de consideración por'parte de cualquier eventual pliego particular de condiciones, salvo en circunstancias especiales --véase 2.6 -, en tanto que el residuo insoluble podría ser tomado en cuenta, sobre todo por lo que se refiere a las máximas categorías o calidades de cemento portland.

\subsection{FL PROBLEMA DE "LA CAL"}

A los efectos de circunstanciales pliegos particulares o especiales de condiciones el concepto genérico de "cal" del cemento y los específicos de "total", "combinada", "libre", "bidratada", "carbonatada", "primaria", "secundaria", etc., constituyen el verdadero caballo de batalla, por el confusionismo que suele existir en torno de estos conceptos, y por el peligro de "legislar" inadecuada o vanamente a consecuencia de ello. En lo que sigue se trata de dar o de aclarar ideas al respecto.

Para ello conviene distinguir desde un principio entre "clínker", "cemento anhidro", "yeso" y "cemento hidratado", como materiales en cuya composición y constitución interviene "la cal" en una u otra forma.

\subsubsection{La cal del clínker.}

En el clínker hay que considerar la "cal total" $\left({ }^{C} C_{t k}\right)$ que es toda la que interviene en la composición, y que se determina globalmente por análisis químico ordinario del clínker. Esta "cal total" se descompone en dos sumandos: "cal combinada" $\left(\mathrm{C}_{\mathrm{ck}}\right)$ y "cal libre" $\left(\mathrm{C}_{\mathrm{T}_{\mathrm{k}}}\right)$. La "cal combinada" constituye la casi totalidad de la "cal total" y forma compuestos hidráulicos (silicatos y aluminatos cálcicos); la "cal libre" es la que en el proceso de sinterización del crudo para obtener el clínker ha quedado al final sin combinar, es decir, "libre" como óxido cálcico CaO, y por lo tanto no forma silicatos ni aluminatos cálcicos. La "cal libre" del clínker puede ser "primaria" o "secundaria", según que, respectivamente, en ningún momento de la sinterización del 
crudo haya estado combinada, o lo haya estado, pero se haya liberado después como consecuencia de un proceso de resorción o descomposición del constituyente hidráulico del que pasajeramente formó parte. Es posible que, a determinados efectos, la "cal libre primaria" y la "cal libre secundaria" se comporten de forma distinta en una cierta medida.

La "cal libre primaria y secundaria" se determina mediante los correspondientes métodos analíticos especiales, (35), -véase 2.3.5-, en tanto que la "cal combinada" no se determina por ningún método, sino que se calcula por diferencia entre la "cal total" y la "cal libre".

\subsubsection{La cal del cemento anhidro y la cal del yeso.}

De forma análoga en el cemento anhidro hay que considerar la "cal total" $\left(\mathrm{C}_{\mathrm{tza}}\right)$, que es la que se determina globalmente por análisis químico ordinario del cemento. Esta "cal total" se descompone en dos sumandos: "cal combinada" ( $\left.\mathrm{C}_{\text {eza }}\right)$ y "cal libre" $\left(\mathrm{C}_{\mathrm{lza}}\right)$. La "cal combinada" $\left(\mathrm{C}_{\mathrm{ckza}}\right)$ del cemento anhidro constituye la casi totalidad de la "cal total" del mismo y se descompone, a su vez, en otros dos sumandos: la "cal combinada" $\left(\mathrm{C}_{\mathrm{ck}}^{\prime}\right)$ de la parte alicuota del clínker de que consta el cemento, la cual forma compuestos hidráulicos (silicatos y aluminatos cálcicos) y la "cal del yeso" $\left(\mathrm{C}_{\mathrm{cy}}^{\prime}\right)$ correspondiente a la parte alícuota de este material que contiene el cemento, la cual no forma compuestos hidráulicos, sino sulfato cálcico. La "cal libre" $\left(\mathrm{C}_{1 \mathrm{za}}\right)$ es la correspondiente a la parte alícuota del clínker presente en el cemento $\left(\mathrm{C}_{1 \mathrm{k}}^{\prime}\right)$ $\mathrm{y}$ tampoco forma compuestos hidráulicos. Esta "cal libre" se determina por los mismos métodos especiales indicados en el caso del clínker, (35). La "cal del yeso" $\left(\mathrm{C}_{\text {с }}^{\prime}\right)$ se calcula en función del valor analítico de $\mathrm{SO}_{3}$ del cemento, admitiendo sin error sensible que el clínker no contiene azufre en forma de sulfatos, o que si lo contiene es en pequeñísimas dosis; de cualquier modo, los sulfatos (alcalinos o cálcicos) ה n? clínker se computan como yeso, y la cal correspondiente como "cal del yeso". La "cal combinada" $\left(\mathrm{C}^{\prime}{ }_{\mathrm{ck}}\right)$ se calcula por diferencia entre la "cal total" $\left(\mathrm{C}_{\mathrm{tza}}\right)$ y la suma de la "cal del yeso" $\left(\mathrm{C}_{\mathrm{cy}}^{\prime}\right)$-calculada, a su vez_y de la "cal libre" $\left(\mathrm{C}_{\mathrm{k}}\right)$-determinada analíticamente-.

Todas estas "cales" que hasta el momento han sido mencionadas se determinan o calculan y se expresan como óxido cálcico, CaO. Si se utiliza para este compuesto el símbolo convencional abreviado $\mathrm{C}$, usual en la química del cemento, con los subíndices anteriores, lo que precede puede resumirse cuantitativa y esquemáticamente de este modo:

$$
\begin{array}{lr}
\mathrm{C}_{\mathrm{tk}}=\mathrm{C}_{\mathrm{ck}}+\mathrm{C}_{\mathrm{tk}} & \\
\mathrm{C}_{\mathrm{tza}}=\mathrm{C}_{\mathrm{cza}}+\mathrm{C}_{\mathrm{zza}} & \mathrm{C}_{\mathrm{cza}}=\mathrm{C}_{\mathrm{ck}}^{\prime}+\mathrm{C}_{\mathrm{cy}}^{\prime} \\
\mathrm{C}_{\mathrm{tza}}=\mathrm{C}_{\mathrm{ck}}^{\prime}+\mathrm{C}_{\mathrm{cy}}^{\prime}+\mathrm{C}_{\mathrm{lza}} & \mathrm{C}_{\mathrm{lza}}=\mathrm{C}_{\mathrm{lk}}^{\prime} \\
\mathrm{C}_{\mathrm{tzan}}=\mathrm{C}_{\mathrm{ck}}^{\prime}+\mathrm{C}_{\mathrm{lk}}^{\prime}+\mathrm{C}_{\mathrm{cy}}^{\prime} . &
\end{array}
$$

Conviene insistir en que $\mathrm{C}_{\mathrm{tk}}, \mathrm{C}_{\mathrm{lk}}, \mathrm{C}_{\mathrm{tzn}}$ y $\mathrm{C}_{\mathrm{kzn}}$ (o su igual $\mathrm{C}_{n, \text { ) }}^{\prime}$ ) son valores que, bien sea en el clínker, o bien en el cemento anhidro, pueden ser determinados analitica mente. En tanto que $\mathrm{C}_{\mathrm{ck}}, \mathrm{C}_{\mathrm{cza}}, \mathrm{C}_{\mathrm{cks}}^{\prime} \mathrm{y} \mathrm{C}_{\mathrm{cy}}^{\prime}$ son valores que en el caso del clínker o en el 
caso del cemento pueden ser calculados por diferencia, o a partir del resto del análisis químico de uno u otro material, o del análisis del yeso, en cada caso.

Para mayor claridad se detallan estos conceptos y relaciones en el caso numérico concreto dado por vía de ejemplo en el Cuadro 1:

CUADRO 1

\begin{tabular}{|c|c|c|c|c|c|c|}
\hline \multicolumn{2}{|c|}{ Conceptcs analíticos } & \multirow{2}{*}{$\frac{21,00}{2 \text { Clínker } 100 \%}$} & \multirow{2}{*}{$\frac{\text { Yeso } 100 \%}{-}$} & \multicolumn{3}{|c|}{ Clinker $95 \%+$ Yeso $5 \%=$ Cemento $100 \%$} \\
\hline Sílice & $\mathrm{SiO}_{2}(\mathrm{~S})$ & & & 19,95 & - & 19,95 \\
\hline Alúmina & $\mathrm{Al}_{2} \mathrm{O}_{3}$ (A) & 6,00 & - & 5,70 & 一 & 5,70 \\
\hline Oxido férrico & $\mathrm{Fe}_{2} \mathrm{O}_{3}(\mathrm{~F})$ & 3,00 & - & 2,85 & 一 & 2,85 \\
\hline Cal total & $\mathrm{CaO}(\mathrm{C})$ & $\mathrm{C}_{\mathrm{tk}}=66,00$ & $\mathrm{C}_{\mathrm{ty}}=32,00$ & $\mathrm{C}_{\mathrm{tk}}^{\prime}=62,70$ & $\mathrm{C}^{\prime}{ }_{\mathrm{ty}}=1,60$ & $\mathrm{C}_{\text {tza }}=64,30$ \\
\hline Trióxido de azufre & $\mathrm{SO}_{3}(\mathrm{~s})$ & 0,00 & 45,50 & 0,00 & 2,30 & 2,30 \\
\hline Resto hasta $100 \%$ & (R) & 4,00 & 22,50 & 3,80 & 1,10 & 4,90 \\
\hline Total \% & & 100,00 & 100,00 & 95,00 & 5,00 & 100,00 \\
\hline $\begin{array}{l}\text { "Cal libre" } \\
\text { "Cal combinada" }\end{array}$ & & $\begin{array}{l}\mathrm{C}_{\mathrm{Lk}}=1,00 \\
\mathrm{C}_{\mathrm{ck}}=65,00\end{array}$ & $\begin{array}{c}- \\
\mathrm{C}_{\mathrm{cy}}=32,00\end{array}$ & $\begin{array}{l}\mathrm{C}_{\mathrm{lk}}^{\prime}=0,95 \\
\mathrm{C}_{\mathrm{ck}}^{\prime}=61,75\end{array}$ & $\mathrm{C}_{\mathrm{cy}}^{\prime}=1,60$ & $\begin{aligned} \mathrm{C}_{1 \mathrm{za}} & =0,9 \mathrm{k} \\
\mathrm{C}_{\mathrm{C}} & =63,35\end{aligned}$ \\
\hline $\begin{aligned} \mathrm{c}_{\mathrm{t} y}= & \text { "cal } \\
\mathrm{C}_{\mathrm{cy}}= & \text { "cal } \\
\mathrm{C}_{\mathrm{tk}}^{\prime}= & { }^{\prime c} \mathrm{cal} \\
\mathrm{C}_{\mathrm{ty}}^{\prime}= & \text { "cal } \\
& \quad \text { iguai } \\
& \text { cemen }\end{aligned}$ & $\begin{array}{l}\text { al" del yes } \\
\text { nbinada" } d \\
\text { al" de la pa } \\
\text { al" de la p } \\
\text { la "cal cor } \\
\text { anhidro Co }\end{array}$ & $\begin{array}{l}\text { yeso (igual } \\
\text { alícuota de } \\
\text { te alícuota d } \\
\text { inada" de I }\end{array}$ & $\begin{array}{l}\text { a la "cal } \\
\text { clínker con } \\
\text { de yeso cont } \\
\text { la parte alic }\end{array}$ & $\begin{array}{l}\text { total" del ye } \\
\text { tenida en el c } \\
\text { tenida en el } \\
\text { uota de yeso }\end{array}$ & $\begin{array}{l}\text { eso } \mathrm{C}_{\mathrm{ty}} \text { ); } \\
\text { cemento anhi } \\
\text { cemento anh } \\
\text { contenida }\end{array}$ & $\begin{array}{l}\text { idro; } \\
\text { hidro } \\
\text { en el }\end{array}$ \\
\hline
\end{tabular}

\subsubsection{La cal del cemento hidratado.}

Paralelamente a lo expuesto en el caso del cemento anhidro, en el caso del cemento hidratado cabe considerar la "cal total" $\left(\mathrm{C}_{\mathrm{tzh}}\right)$ que es la que se determinaría globalmente por análisis químico ordinario. Esta "cal total" se descompone en varios sumandos, a saber: "cal combinada" $\left(\mathrm{C}_{\text {czh }}\right)$ y "cal liberada" $\left(\mathrm{C}_{\mathrm{lzh}}\right)$. La "cal combinada" del cemento hidratado no constituye sino una parte de la "cal total" del mismo, y precisamente aquélla que forma compuestos hidráulicos simples y complejos (silicatos, aluminatos, ferritos, sulfoaluminatos, sulfoferritos y silicoaluminatos cálcicos hidratados). La "cal liberada" constituye el resto de la "cal total" y no forma parte de los citados compuestos hidratados. Esta "cal liberada" se encuentra inicialmente como hidróxido cálcico $\mathrm{Ca}(\mathrm{OH})_{2}$ ("portlandita"), pero por acción atmosférica o de eventuales aguas carbónicas puede carbonatarse en parte o disolverse. En el primer caso se transforma en carbonato cálcico, con lo cual queda parcialmente "combinada" a posteriori, aunque sin formar compuestos hidráulicos. En el segundo caso puede desaparecer o formar eflorescencias, según los casos. 
La "cal total" del cemento anhidro da lugar indudablemente a la "cal total" del cemento hidratado, así como la "cal libre" del primero se computa totalmente como "cal liberada" en el segundo. Pero la "cal combinada" del cemento anhidro no sólo da lugar a la totalidad de la "cal combinada" del cemento hidratado, sino que en una parte considerable da también lugar al resto de la "cal liberada" del mismo. La falta de paralelismo o de correspondencia unívoca y recíproca, prescindiendo de un eventual y ligerísimo proceso de carbonatación, es atribuible a la "cal combinada" del cemento anhidro. Estas relaciones quedan de manifiesto en el esquema siguiente:

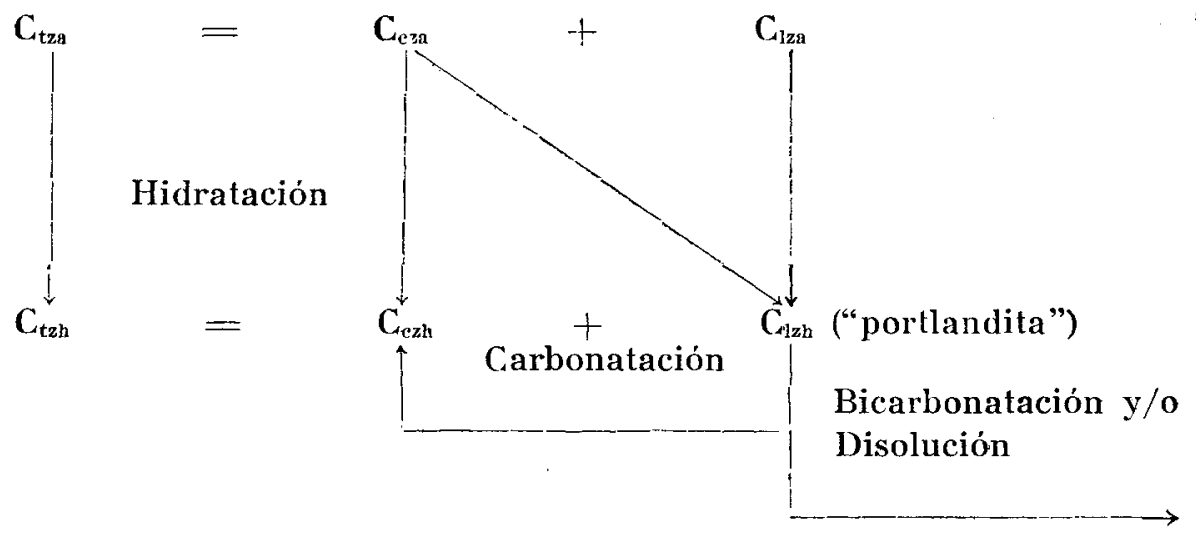

A efectos cuantitativos más detallados, relativos a $\mathrm{C}_{\mathrm{czh}}$ y a $\mathrm{C}_{\mathrm{gzh}}$ en función de $\mathrm{C}_{\mathrm{cza}}$ principalmente, hay que considerar en primer lugar que, de los constituyentes principales del cemento portland, los silicatos liberan cal en la hidratación, en tanto que los aluminatos y los ferritos la fijan o combinan; y en segundo lugar que, de los dos silicatos, el tricálcico libera más cal que el bicálcico (en la relación aproximada de 1,5 a 0,5 moles de $\mathrm{Ca}(\mathrm{OH})_{2}$ por mol de silicato).

Mediante el simbolismo comúnmente utilizado en la química del cemento, estos wacanismos pueden esquematizarse de forma simplificada, (20), así:

$$
\begin{aligned}
& 2 \mathrm{C}_{3} \mathrm{~S}+5 \mathrm{H} \longrightarrow \mathrm{C}_{2} \mathrm{SH}+\mathrm{CSH}+3 \mathrm{CH} \\
& 2 \mathrm{C}_{2} \mathrm{~S}+3 \mathrm{H} \longrightarrow \mathrm{C}_{2} \mathrm{SH}+\mathrm{CSH}+\mathrm{CH} \\
& \mathrm{C}_{3} \mathrm{~A}+\mathrm{CH}+11 \mathrm{H} \longrightarrow \mathrm{C}_{4} \mathrm{AH}_{12} \\
& \mathrm{C}_{4} \mathrm{AF}+2 \mathrm{CH}+10 \mathrm{H} \longrightarrow \mathrm{C}_{3} \mathrm{AH}_{6}+\mathrm{C}_{3} \mathrm{FH}_{6}
\end{aligned}
$$

Pnr consiguiente, teniendo esto en cuenta y efectuando el adecuado cálculo polencial, (18), a partir de los datos de composición del cemento del Cuadro 1 , se tienen los resultados del Cuadro 2: 
CUADRO 2

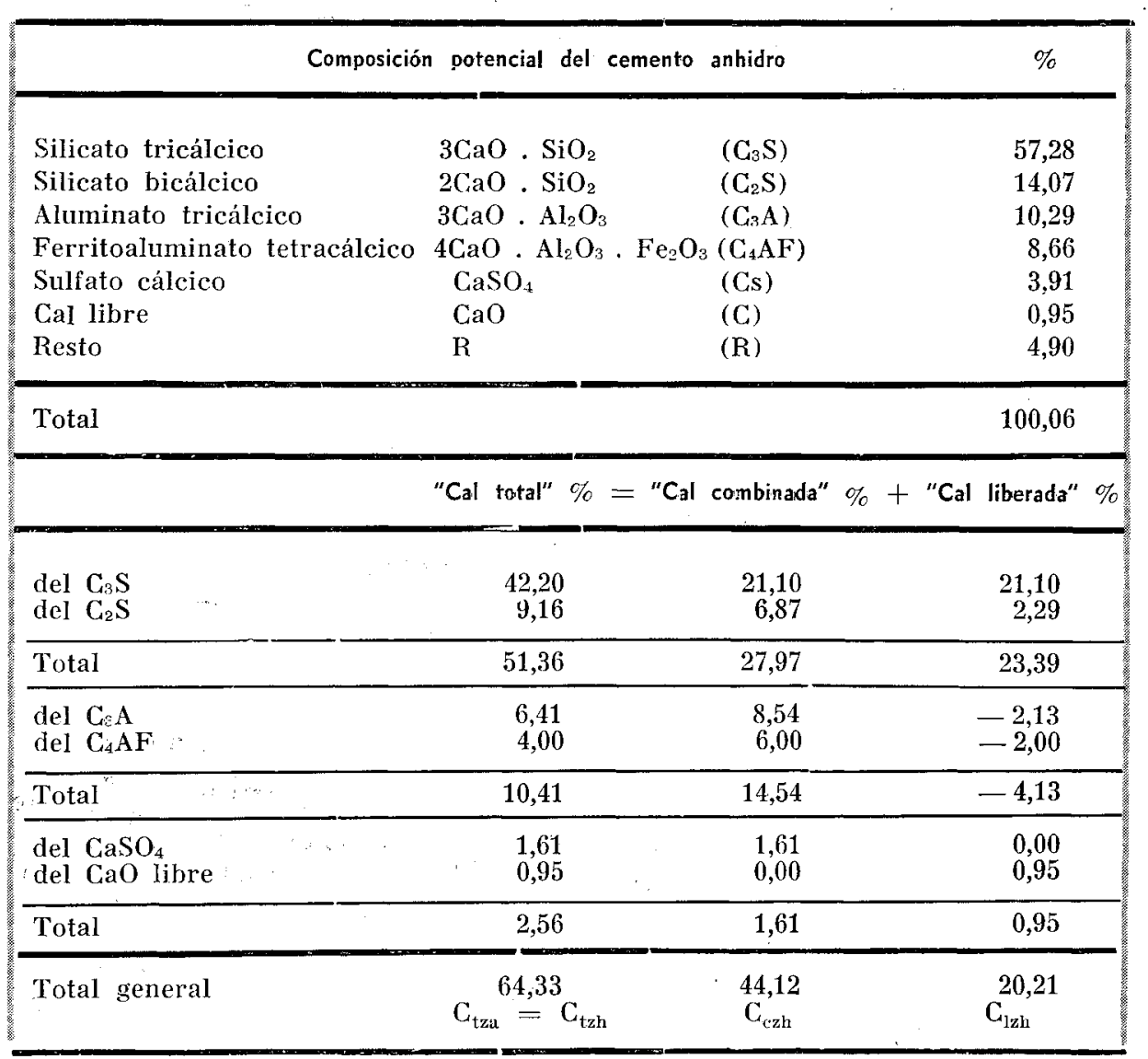

En el cuadro 2 se han admitido unas condiciones extremas - [IIIa] y [IIIb] - en lo que respecta a la hidratación del $\mathrm{C}_{3} \mathrm{~A}$ y del $\mathrm{C}_{4} \mathrm{AF}$, por lo cual el valor $\mathrm{C}_{1 \mathrm{hh}}=20,21$ por 100 tiene el carácter de mínimo. En las condiciones extremas opuestas, considerando la formación de sulfoaluminatos y de sulfoferritos, en lugar de [IIIa] y [IIIb] se tendrían las dos alternativas a) y b) de [IV]:

$$
\begin{aligned}
& \mathrm{C}_{3} \mathrm{~A}+\mathrm{CsH}_{2}+10 \mathrm{H} \rightarrow \mathrm{C}_{3} \mathrm{~A} \cdot \mathrm{Cs} \cdot \mathrm{H}_{12} \\
& \text { [IVa] } \\
& \mathrm{C}_{4} \mathrm{AF}+2 \mathrm{CsH}_{2}+2 \mathrm{CH}+18 \mathrm{H} \rightarrow \mathrm{C}_{3} \mathrm{~A} \cdot \mathrm{Cs} \cdot \mathrm{H}_{12}+\mathrm{C}_{3} \mathrm{~F} \cdot \mathrm{Cs} \cdot \mathrm{H}_{12}[\mathrm{IVb}]
\end{aligned}
$$

La consideración de estas nuevas alternativas da lugar al Cuadro 3:

CUADRO 3

\begin{tabular}{|cccc|}
\hline & Total & Para [IV] & Restantes para [III] \\
\hline $\mathrm{C}_{\curvearrowleft} \mathrm{A}$ & 10,29 & 7,76 & 2,53 \\
$\mathrm{C}\lrcorner \mathrm{AF}$ & 8,66 & 6,98 & 1,68 \\
\hline
\end{tabular}


En la realidad no podrían darse de forma simultánea y total las posibilidades [III] y [IV], sino que se darían precisamente la [IIIa] y la [IVb], o bien la [IImb] y la [IVa], cada uno de cuyos casos convierte la parte inferior del Cuadro 2 en cada uno de los Cuadros 4 y 5, respectivamente:

CUADRO 4

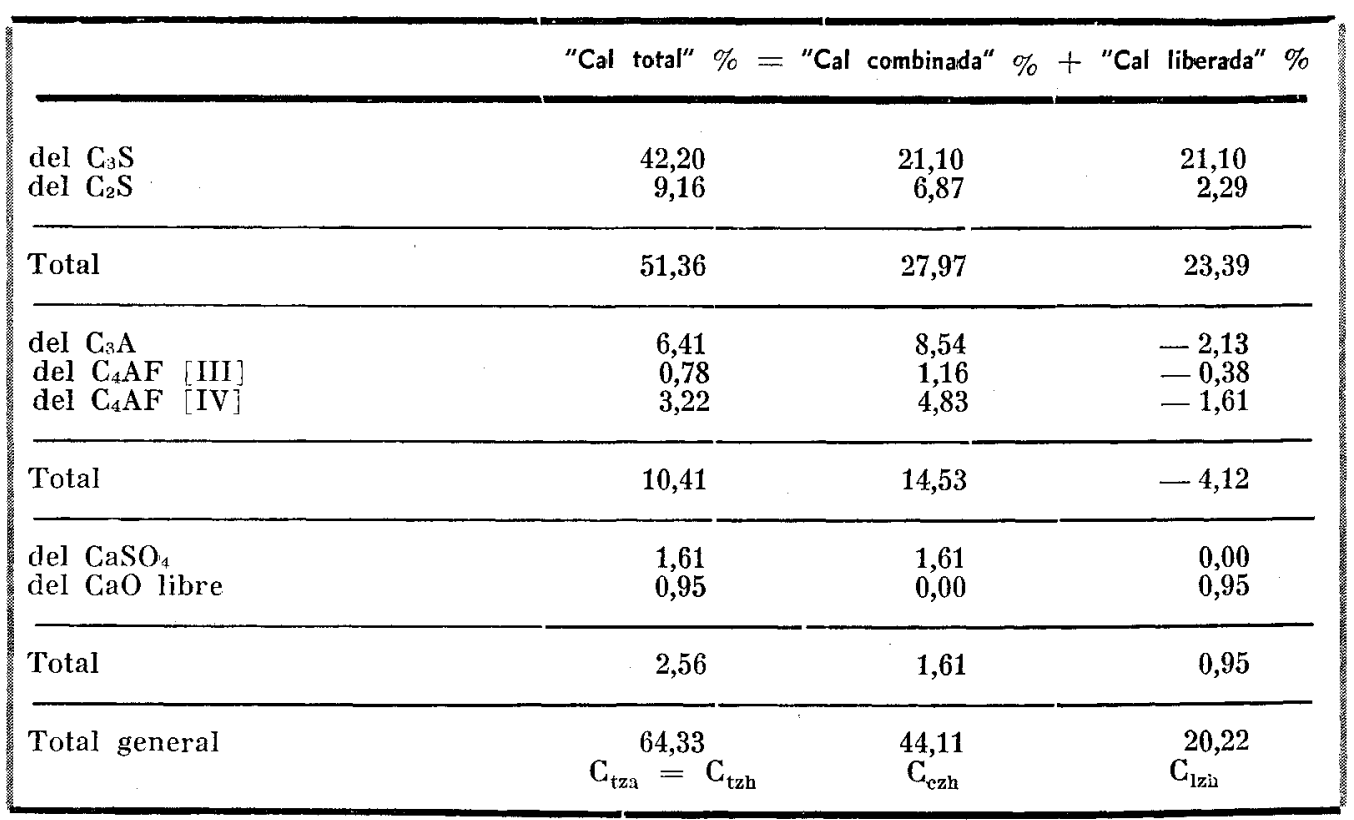

CUADRO 5

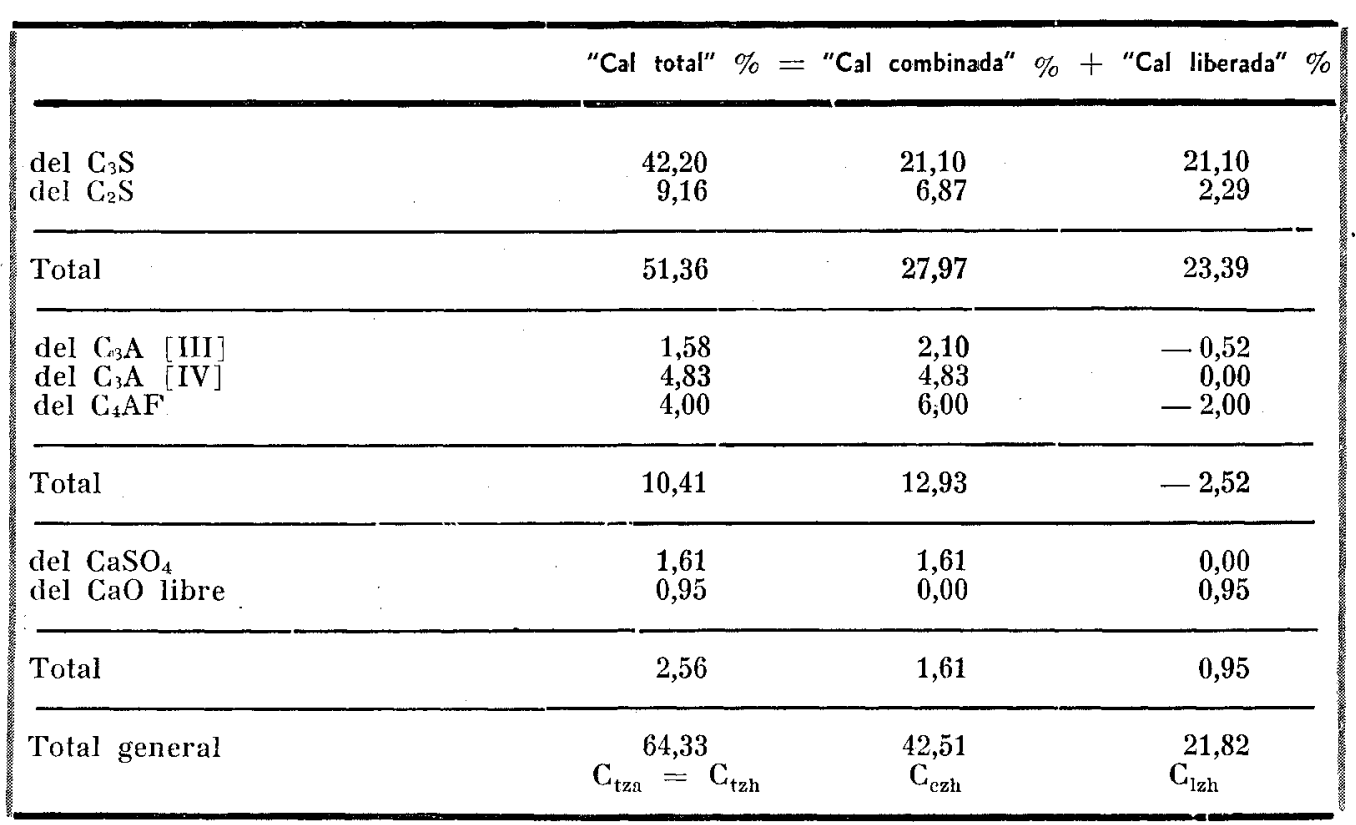

Por la misma razón de condiciones extremas antes invocada el valor $\mathrm{C}_{\mathrm{lzh}}=21,82$ del Cuadro 5 tiene el carácter de un máximo. 
Los resultados finales son iguales en el caso de los Cuadros 2 y 4 , y muy poco distintos en el caso del Cuadro 5. Ponen de relieve numéricamente los siguientes hechos ya señalados:

i) que prácticamente la totalidad de la "cal liberada" procede de los silicatos;

ii) que el silicato tricálcico, por su mayor presencia en el cemento (en general) y por su mayor cesión de "cal liberada" es el constituyente que produce mayor aportación de ésta;

iii) que aun suponiendo procesos de hidratación extremos opuestos para los aluminatos, apenas si se modifica la cantidad total de "cal liberada" del cemento hidratado;

iv) que esta "cal liberada" es aproximadamente y en promedio del orden de $1 / 3$ de la "cal total" del cemento anhidro;

v) que la aportación de la "cal libre" del cemento anhidro $\mathrm{C}_{\mathrm{lk}}^{\prime}$ a la "cal liberada" del cemento hidratado puede considerarse en promedio del orden del 5 por ciento de la "cal liberada" total, valor que puede calificarse de poco importante.

También en este caso conviene señalar que $\mathrm{C}_{\mathrm{tzh}}$, como su igual $\mathrm{C}_{\mathrm{tza}}$, puede ser determinado analiticamente. En cambio, existen serias dificultades para poder determinar analíticamente $\mathrm{C}_{\mathrm{zhh}}$, aunque pudiera pensarse que es posible aplicar los mismos métodos que para determinar $\mathrm{C}_{\mathrm{lk}}$ o $\mathrm{C}_{1 \mathrm{za}},(35)$, - - véase 2.3.5--. No puede determinarse $\mathrm{C}_{\text {czh }}$, ni calcularse por diferencia entre $\mathrm{C}_{\mathrm{tzh}}$ y $\mathrm{C}_{\mathrm{lzh}}$, al desconocerse el último de estos valores. Tampoco puede determinarse prácticamente ninguno de los valores intermedios de "cal total", "cal combinada" o "cal liberada" calculados y expuestos en los Guadros 2,4 y 5 .

\subsubsection{La cal en las normas para cemento.}

A lo expuesto en los puntos anteriores se debe muy probablemente y en buena parte el hecho de que las normas para cemento no incluyan ninguna especificación relativa a la "cal libre" $\mathrm{C}_{\mathrm{lza}}$, ni a la "cal total" $\mathrm{C}_{\mathrm{tzza}}$. Y así, en la relación de cuarenta y cuatro normas para cemento portland que figuran en el CEMBUREAU ninguna de ellas prescribe nada al respecto - véase 2.4-.

Directamente tampoco se hace especificación en cuanto a la "cal combinada" $\mathrm{C}_{\text {crza }}$ o bien $\mathrm{C}_{\text {ck }}^{\prime}$, aunque indirectamente sí, a través del módulo hidráulico $\mathrm{MH}$ o relación $\mathrm{C} / \mathrm{S}+\mathrm{A}+\mathrm{F},(18)$. De las cuarenta y cuatro normas citadas, ocho especifican en la forma siguiente: seis estipulan que MH debe ser superior a 1,7 (una de ellas considera muy lógica y acertadamente que el numerador de la expresión del módulo hidráulico debe ser $\mathrm{C}-0,7 \mathrm{SO}_{3}$ en lugar de $\mathrm{C}$; otra de ellas impone como condición adicional que el módulo hidráulico debe ser menor o igual que $2,4 \mathrm{y}$ considera que los compuestos de manganeso expresados como $\mathrm{Mn}_{2} \mathrm{O}_{3}$ deben sumarse a los sesquióxidos en el denominador de la expresión del módulo hidráulico); una estipula que el módulo hidráulico sea igual o mayor que 1,8; una prescribe que este módulo sea igual o mayor que 2. En el ejemplo numérico del Cuadro 1 puede apreciarse que MH oscila entre 2,16 y 2,26 según el criterio que se adopte respecto del valor de C. En realidad, cualesquiera de las limitaciones señaladas las cumplen prácticamente todos los cementos portland sin adiciones, porque son obligadas para la buena marcha técnica y económica de la fabricación del clínker. 
Otra especificación indirecta, si así se quiere considerar, respecto de la "cal combinada" $\mathrm{C}_{\mathrm{ck}}^{\prime}$, es la hecha a través del factor de saturación de cal LSF ("lime saturation factor") o relación: $\mathrm{C}-0,7 \mathrm{SO}_{3} / 2,8 \mathrm{~S}+1,2 \mathrm{~A}+0,65 \mathrm{~F},(18)$. De las cuarenta y cuatro normas mencionadas anteriormente otras ocho, distintas de las ocho anteriores salvo una, especifican del modo siguiente: seis esiipulan $0,66 \leqslant \mathrm{LSF} \leqslant 1,02$ (una de ellas considera 0,6 como límite inferior y adopta 2,85 en vez de 2,8 como coeficiente de la silice; tres de ellas consideran además la limitación $1,95 \mathrm{~S}+1,2 \mathrm{~A}+0,65 \mathrm{~F} \leqslant \mathrm{C}-0,7 \mathrm{SO}_{3} \leqslant$ $\leqslant 2,4 \mathrm{~S}+1,2 \mathrm{~A}+0,65 \mathrm{~F}$ para comentos portland de bajo calor de hidratación — véase 2.5.2-); las dos restantes consideran el valor de $\mathrm{C}$ en vez de $\mathrm{C}-0,7 \mathrm{SO}_{3}$ con las mismas limitaciones para LSF una de ellas, y con la condición $2 / 3(2,8 \mathrm{~S}+1,2 \mathrm{~A}+0,65 \mathrm{~F}) \leqslant \mathrm{C} \leqslant$ $\leqslant 2,8 \mathrm{~S}+1,2 \mathrm{~A}+0,65 \mathrm{~F}$ la otra. En el ejemplo numérico del Cuadro 1 se puede apreciar que LSF oscila entre 0,96 y 1,00 según el valor que se adopte para el numerador de la correspondiente expresión.

\subsubsection{Los métodos para la determinación de la cal libre.}

Si bien es cierto que ninguna norma estipula nada acerca del contenido de "cal libre" del cemento, las hay, en cambio, que incluyen métodos para la determinación analítica de $\mathrm{C}_{\mathrm{lk}}$ ("cal libre" del clínker -véase 2.3.1-) o de $\mathrm{C}_{\mathrm{lza}}=\mathrm{C}_{\mathrm{lk}}$ ("cal libre" de cemento - véase $2.3: 2-$ ). Entre tales normas cabe citar la norteamericana, (35), y la española, (10).

En la primera de estas normas se hace constar que los métodos se refieren a la determinación de óxido cálcico libre $\mathrm{CaO}$ en clínker de cemento portland de fabricación reciente, y que cuando se aplica a cemento portland o a clínker meteorizado, lo que se determina es la suma de óxido cálcico $\mathrm{CaO}$ y del posible hidróxido cálcico $\mathrm{Ca}(\mathrm{OH})_{2}$ que pudiera haberse formado como consecuencia de la meteorización, pue el método no distingue entre uno y otro compuesto. A esto puede añadirse que si la meteorización es más profunda y no se para en la primera fase de hidratación,

$$
\mathrm{CaO}+\mathrm{H}_{2} \mathrm{O} \longrightarrow \mathrm{Ca}(\mathrm{OH})_{2},
$$

sino que prosigue en una segunda etapa de carbonatación,

$$
\mathrm{Ca}(\mathrm{OH})_{2}+\mathrm{CO}_{2} \longrightarrow \mathrm{CaCO}_{3}+\mathrm{H}_{2} \mathrm{O},
$$

el método analítico no detecta la parte de "cal libre" que se ha carbonatado, porque al hacerlo ha dejado dè ser libre.

\subsubsection{La cal libre y la expansión.}

Uno de los problemas a que puede dar lugar un contenido elevado de "cal libre" $\mathrm{C}_{\mathrm{lza}}$ en el cemento es el de la expansión diferida, pues la hidratación de dicha cal, que transcurre con aumento de volumen, es muy lenta y tiene lugar cuando las masas fraguadas ya son rígidas, lo cual puede producir fallos de diversos tipos. Es por esta razón por la que la meteorización rebaja el contenido de "cal libre" del cemento, lo cual se utiliza en fabricación para reducir o eliminar su posible comportamiento expansivo, como consecuencia de su contenido de "cal libre". Claro está que en esta utilización se corre el riesgo de mermar la capacidad hidráulica del cemento.

Parece que las normas deben tener todo esto en cuenta, $y$ de hecho lo tienen. Y si bien no estipulan nada en cuanto a contenido máximo tolerable de "cal libre" potencialmente expansiva, en lugar de ello prescriben en todos los casos ensayos de expansión en condiciones más drásticas que las reales de empleo del cemento: Uno 
de estos ensayos es "el del autoclave", (26), propugnado por doce de las cuarenta y cuatro normas reseñadas por el CEMBUREAU. Los resultados del ensayo son tales que si un cemento portland los da satisfactorios, puede asegurarse sin más que el cemento no será expansivo por sí mismo, en tanto que si no entran dentro de la especificación no puede afirmarse que el cemento sea expansivo necesariamente. Es decir, los resultados del ensayo sitúan al material del lado de la seguridad. El ensayo tiene además la ventaja de que mediante él no sólo se acusa la expansión debida a la "cal libre", sino también la que pudiera producirse por cualquier otra causa inherente a la composición o constitución del cemento portland - véase 2.2.1-.. El ensayo de expansión en autoclave es prescriptivo en la norma española, (10), para los cementos portland, los siderúrgicos y los puzolánicos, aspecto éste del que se tratará en otro lugar, (24), -véase 2.1-.

Por otra parte, una de las diferencias a las que se ha hecho alusión en 2.3, en cuanto al distinto comportamiento de la "cal libre primaria" y de la "cal libre secundaria" tal vez se dé precisamente en el terreno de la expansión. Es posible que ambas "cales libres" tengan diversa capacidad expansiva a largo plazo, en el sentido de ser mayor la de la "cal libre primaria", en función de ser una cal de grano cristalino más grueso y "calcinada a muerte", en tanto que la "cal libre secundaria" es una cal de grano mucho más fino, se halla más dispersa y es, en cierto modo, una "cal naciente", bastante más reactiva a más corto plazo. Ello puede dar lugar a que de dos cementos con igual contenido de "cal libre" (total), uno resulte expansivo (o más expansivo) en el ensayo del autoclave, en relación con el otro. El primero sería aquél cuya "cal libre total" fuese por entero o en gran medida "primaria". El segundo sería un cemento no expansivo o menos expansivo y aceptable en muchos casos, siendo así que una limitación de "cal libre" con miras a prevenir un supuesto péligro de expansión lo rechazaría injustamente.

En conclusión, por lo que hace al posible comportamiento expansivo de un cemento portland, habida cuenta del ejemplo de todas las normas nacionales de los distintos países, y considerado el hecho de ser prescriptivo el ensayo de expansión en autoclave en el PCCH-64, no es necesario ni aconsejable establecer una limitación para la "cal libre" (ni para ninguna otra "cal") en cualquier eventual pliego particular de condiciones para cementos portland.

\subsubsection{La cal liberada y la durabilidad.}

Otro problema a que puede dar lugar un contenido elevado de "cal liberada" $\mathrm{C}_{\mathrm{lzh}}$ en el cemento hidratado es el del "deslavado" y disolución de dicha cal ("portlandita") por aguas muy blandas o puras, o el del ataque de la misma por aguas ácidas.

Como indican los Cuadros 2, 4 y 5 -véase 2.3.3-, esta "cal liberada" se debe casi en exclusiva a los silicatos del cemento, y de ellos, aproximadamente en un $90 \%$ como mínimo al tricálcico $\mathrm{C}_{3} \mathrm{~S}$. La contribución de la "cal libre" del cemento anhidro $\mathrm{C}_{\mathrm{zza}}$ a la "cal liberada" del cemento hidratado $\mathrm{C}_{\mathrm{zzh}}$ es sólo del orden del $5 \%$, esto es, muy poco importante -véase 2.3.3-.

Por lo tanto, aún es menos necesario y aconsejable imponer en cualquier eventual pliego particular una limitación a la "cal libre" del cemento portland, con miras a garantizar en cualquier medida, por modesta que pudiera ser, la durabilidad del cemento hidratado.

Lo que si tendría sentido, en cambio, sería limitar con tal objeto precisamente el contenido máximo de silicato tricálcico $\mathrm{C}_{3} \mathrm{~S}$-véase el párrafo final del pun- 
to 2.4-, o el mínimo de silicato bicálcico $\mathrm{C}_{2} \mathrm{~S}$, o ambos, pero de ello se trata con más detalle en los siguientes puntos 2.4.

Aparte de que, cuando la "cal liberada" puede jugar un papel importante en la durabilidad intervienen otros considerandos preponderantes, como es, entre otros, el empleo de cementos distintos de los portland, más adecuados y recomendables para el caso, (20).

\subsection{PRESCRIPCIONES SOBRE LA COMPOSICION POTENCIAL}

La composición potencial calculada a partir de los datos analíticos químicos del cemento portland, es objeto de especificación por parte de once de las cuarenta y cuatro normas reseñadas por el CEMBUREAU, en la forma siguiente: cinco especifican ampliamente sobre máximos de $\mathrm{C}_{3} \mathrm{~S}, \mathrm{C}_{3} \mathrm{~A}$ y $2 \mathrm{C}_{3} \mathrm{~A}+\mathrm{C}_{4} \mathrm{AF}$, así como sobre mínimos de $\mathrm{C}_{2} \mathrm{~S}$, salvo en un caso; en este mismo caso, el único, se prescribe un valor máximo para la suma $\mathrm{C}_{3} \mathrm{~S}+\mathrm{C}_{3} \mathrm{~A}$ (además de otro para $\mathrm{C}_{3} \mathrm{~A}$ ), en lugar de hacerlo para $\mathrm{C}_{3} \mathrm{~S}$ aisladamente ${ }^{*}$. En otro caso distinto se prescribe además la siguiente limitación para el módulo alumino-férrico, (18),: $\mathrm{MF}=\mathrm{A} / \mathrm{F} \geqslant 0,66$, lo que equivale a que se tenga que satisfacer además otra relación entre $\mathrm{C}_{3} \mathrm{~A}$ y $\mathrm{C}_{4} \mathrm{AF}$, siendo éste el caso de mayor número de limitaciones en cuanto a composición potencial se refiere. Un solo caso estipula dos límites máximos para $\mathrm{C}_{3} \mathrm{~S}$ y $\mathrm{C}_{3} \mathrm{~A}$ y uno mínimo para $\mathrm{C}_{2} \mathrm{~S}$, con la prescripción adicional de $\mathrm{MF} \geqslant 0,7$, con lo cual son dos las normas que especifican mínimos para el módulo alumino-férrico. En otros cinco casos se prescriben máximos para $\mathrm{C}_{3} \mathrm{~S}$ y para $\mathrm{C}_{3} \mathrm{~A}$, y en un único caso aparte un máximo exclusivo para $\mathrm{C}_{3} \mathrm{~A}$.

Interesa destacar además que, de los cuarenta y cuatro casos, en siete de los incluidos en los once que hacen estipulaciones sobre la composición potencial se prescriben límites para los distintos conceptos de la composición química, excepto precisamente para la "cal total" $\mathrm{C}_{\mathrm{taa}}$, lo cual corrobora lo indicado al final del primer párrafo del punto 2.3.4 y justifica lo expuesto en 2.3.7.

\subsubsection{Consideraciones sobre el cálculo de la composición potencial.}

El cálculo de la composición "potencial" del cemento portland está basado en estudios y conclusiones de DAHL y BOGUE, principalmente, (37). Las normas ASTM, y.concretamente la relativa a cemento, (36), especifican dicho cálculo y los limites de composición potencial resultante, con la observación de que estos límites "no significan necesariamente que los óxidos estén realmente o totalmente presentes en el cemento en la forma de los sunuestos constituyentes potenciales".

Mucho podría añadirse aqui acerca de la parte de realidad y de la parte de ficción en el cálculo y composición potenciales del cemento portland; acerca de la utilidad y limitaciones de dicho cálculo; sobre las aberraciones y resultados absurdos o incorrectos a que conduce el abuso o el mal uso de dicho cálculo: en torno a su aplicación inadecuada a casos para los que no está previsto, applicación de la que se hace uso más frecuente de lo que se suele suponer; etc. De este tema, del que se ha hecho mención en varias ocasiones, (18), (19) y (38), se ha tratado recientemente con la de bida extensión, (34).

Baste señalar aquí como conclusión general de todo ello, que el cálculo de la composición potencial sólo es aplicable al cemento portland constituido exclusivamente por mezcla de clínker y yeso. Esto que puede parecer una redundancia no lo es, si se

* Igual sucede en la más reciente norma ASTM, (36), para los cementos de moderado calor de hidratación, si no se exige ensayo para la determinación del mismo --véase 2.5.2-. 
tiene en cuenta que el PCCH-64 considera cementos portland y concede esta denominación comercial "... a aquellos que, además de los componentes principales, clínker y piedra de yeso, contengan otras adiciones no nocivas en proporción inferior a 10 por ciento...". Como está bien demostrado, (34), esto invalida toda aplicación, con carácter general al menos, del cálculo potencial, incluso a los cementos portland comerciales.

No obstante, y habida cuenta de lo señalado en el último párrafo del punto 2.3.7, de lo expuesto en $2.4 \mathrm{y}$ de lo que se indica en 2.5 .2 , siempre que se trate de cementos portland sin adiciones, es decir, sin más componentes que los normales clínker y yeso en las debidas proporciones, el cálculo potencial puede constituir una ayuda estimable y puede permitir el establecimiento de limitaciones razonables que sustituyan, a veces con ventaja, a las que la falta o la insuficiencia de los métodos analíticos al uso hacen difícil implantar.

\subsubsection{La composición potencial y la durabilidad.}

Con lo anterior en cuenta, de las cuarenta y cuatro normas reseñadas por el CEMBUREAU son siete, $y$ entre ellas está la española, las que estipulan limitaciones para la composición potencial de los cementos portland denominados "resistentes a sulfatos", equivalentes a los cementos PAS españoles, (10). De las seis normas extranjeras tres prescriben las siguientes condiciones: $\mathrm{C}_{3} \mathrm{~S} \leqslant 50 \%, \mathrm{C}_{3} \mathrm{~A} \leqslant 5 \%$ y $2 \mathrm{C}_{3} \mathrm{~A}+\mathrm{C}_{4} \mathrm{AF} \leqslant$ $\leqslant 20 \%$; otra suprime la última de estas limitaciones; otra sustituye la primera de ellas por ésta: $\mathrm{C}_{3} \mathrm{~S}+\mathrm{C}_{3} \mathrm{~A} \leqslant 55 \%$; la restante impone una limitación única (como la norma española), a saber: $\mathrm{C}_{3} \mathrm{~A} \leqslant 4 \%$ (en el PCCH-64, $\mathrm{C}_{3} \mathrm{~A} \leqslant 5 \%$ ). Parece que, dada la peculiar característica selenitosa de una buena parte del suelo español, (39), y la concurrente condición más que medianamente aluminosa de una notable fracción de los cementos portland españoles, (40) y (41), sería interesante tener en cuenta lo anterior en eventuales pliegos particulares para obras en terrenos yesíferos, a fin de introducir alguna condición más en la composición potencial de los cementos portland PAS que hubieran de ser utilizados. Estas condiciones podrian referirse, además de a $\mathrm{C}_{3} \mathrm{~A}$, a $\mathrm{C}_{3} \mathrm{~S}$ y/o a $2 \mathrm{C}_{3} \mathrm{~A}+\mathrm{C}_{4} \mathrm{AF}$, o bien a $\mathrm{C}_{3} \mathrm{~S}+\mathrm{C}_{3} \mathrm{~A}$ y/o a $2 \mathrm{C}_{3} \mathrm{~A}+\mathrm{C}_{4} \mathrm{AF}$, con los mismos valores límite, por lo menos, que fijan las restantes normas en los casos respectivos.

La condición impuesta por el PCCH-64 para el contenido máximo de $\mathrm{C}_{3} \mathrm{~A}$ de los cementos portland P-350 y P-450 resulta incomprensible y superflua.

\subsection{PRESCRIPCIONES ESPECIALES}

Figuran como tales dentro del PCCH-64 las relativas a los cementos de bajo contenido de álcalis y a los cementos de bajo calor de hidratación.

\subsubsection{Los álcalis del cemento.}

En general, las normas para cemento se refieren muy poco a los álcalis, en el caso de los cementos ordinarios. Tan sólo una de las cuarenta y cuatro normas registradas por el CEMBUREAU fija un máximo de álcalis $\left(\mathrm{Na}_{2} \mathrm{O}+0,658 \mathrm{~K}_{2} \mathrm{O}\right)$ variable entre 0.8 y $1,2 \%$ para distintos tipos de cemento portland. Otras tres normas, entre ellas la española, fijan un máximo de $0,6 \%$ para cementos portland especiales "de bajo contenido de álcalis". Las otras dos normas indican que la condición de cemento "de bajo contenido de álcalis" podrá ser exigida por el usuario, si lo estima oportuno; 
una de ellas añade que tal exigencia sólo está justificada si el cemento ha de utilizarse con áridos potencialmente reactivos con los álcalis del cemento, y que entonces, a juicio del usuario basado en la experiencia, el contenido máximo tolerable de $0,6 \%$ de álcalis puede ser rebajado aún más. Se trata de normas de un país con amplia experiencia en este problema, (36) y (42).

Por otra parte, existe precisamente en dicho país (U.S.A.) un método normalizado para determinar la susceptibilidad de combinaciones de áridos y cementos a reacciones expansivas en que intervienen determinados componentes silícicos de los áridos con los álcalis del cemento, (43). Además, existe otra norma para determinar la reactividad potencial de los propios áridos, (44).

Esto quiere decir que para especificar límites al contenido de álcalis en los cementos portland normales, o de variar los establecidos para los de bajo contenido de álcalis por las normas ordinarias para cemento, debe demostrarse experimentalmente la existencia de una buena razón, en base a los ensayos pertinentes. Si tal razón no existe, no hay por qué imponer con carácter general, aun dentro de un eventual pliego particular, limitaciones al contenido de álcalis de los cementos portland ordinarios, ni, por lo tanto, alterar, aunque sea elevándolo, el límite establecido para los de bajo contenido de álcalis. Por el contrario, lo que sí puede y debe hacerse, de existir razón para ello, es exigir la condición de "cemento portland de bajo contenido de álcalis", e incluso rebajar en el eventual pliego particular el límite máximo tolerado para dicho contenido de álcalis en los citados cementos.

\subsubsection{El calor de hidratación del cemento.}

En quince de las cuarenta y cuatro normas reseñadas por el CEMBUREAU (incluida la norma española) se estipulan cementos portland de moderado o de bajo calor de hidratación. En dos de las normas se preconiza para su determinación el método calorimétrico adiabático y en las restantes, implícita o explícitamente, el método por disolución, (45). En diez casos se fijan límites máximos para el calor de hidratación (en dos de ellos a 3 y a 7 días, y en los ocho restantes a 7 y a 28 días, como en la norma española).

En otras doce de las quince normas se estipulan las condiciones que en cuanto a composición deben cumplir los cementos de bajo calor de hidratación. En nueve de estos doce casos se fijan límites para conceptos relativos a la composición potencial y en los tres casos restantes se señalan condiciones referentes a la composición química (LSF) --véase 2.3.4--..

Los nueve casos afectados por condiciones relativas a la composición potencial incluyen trece cementos, cinco de ellos considerados de bajo calor de hidratación y ocho designados como de moderado calor de hidratación. Para estos últimos se prescriben máximos para $\mathrm{C}_{3} \mathrm{~S}$ y $\mathrm{C}_{3} \mathrm{~A}$ de 50 y de $8 \%$ respectivamente, en todos los casos menos en uno en que se estipula un máximo de $8 \%$ para $\mathrm{C}_{3} \mathrm{~A}$ y otro máximo de $58 \%$ para la suma $\mathrm{C}_{3} \mathrm{~S}+\mathrm{C}_{3} \mathrm{~A}$. En los cinco casos correspondientes a los cementos de bajo calor de hidratación se prescriben, en cuatro de ellos, máximos de $\mathrm{C}_{3} \mathrm{~S}$ y de $\mathrm{C}_{3} \mathrm{~A}$ y mínimos de $\mathrm{C}_{2} \mathrm{~S}$ (de 30,7 y $40 \%$ respectivamente en tres; de 35,7 y $40 \%$ en uno), y máximos de $\mathrm{C}_{3} \mathrm{~S}=40 \%, \mathrm{C}_{3} \mathrm{~A}=8 \%, \mathrm{C}_{4} \mathrm{AF}=20 \%$ y un mínimo de $\mathrm{C}_{2} \mathrm{~S}=35 \%$, en el caso restante.

En cuatro normas de las quince se estipulan simultáneamente límites para el calor de hidratación a 7 y a 28 días, y condiciones para la composición potencial; tres 
de estas normas fijan los límites de 70 y $80 \mathrm{cal} / \mathrm{g}$ para cada edad respectiva y para cementos de moderado calor de hidratación; la otra norma fija límites correspondientes de 65 y $75 \mathrm{cal} / \mathrm{g}$ para cementos de bajo calor de hidratación. Estos mismos límites son adoptados por otras dos normas (una de ellas la española), y el primero de ellos por otra norma más, para cementos de bajo calor de hidratación, pero sin imponer condiciones a la composición potencial. Finalmente, de tres normas que tampoco imponen tales condiciones, dos estipulan los límites de 60 y $70 \mathrm{cal} / \mathrm{g}$ a 7 y a 28 dias, respectivamente, y una fija límites de 50 y $60 \mathrm{cal} / \mathrm{g}$ a 3 y a $z$ días para cementos de bajo calor de hidratación.

El PCCH-64 preseribe por su parte máximos de 65 y $75 \mathrm{cal} / \mathrm{g}$ para el calor de hidratación de cementos de bajo calor de hidratación, valores que coinciden prácticamente con las medias de las normas restantes. La norma española, si bien no relaciona directamente el calor de hidratación con la composición potencial, ni en tal sentido fija límites a ésta, estipula, en cambio, un máximo $\mathrm{C}_{3} \mathrm{~A}=3 \overline{5} \%$ en el caso de "cementos para presas". Esta prescripción coincide prácticamente con una de las varias (tres o cuatro, según los casos) que cinco de las normas extranjeras estipulan para los cementos de bajo calor de hidratación.

Cabe deducir de ello que, según el PCCH 64, tímidamente se intenta recomendar para empleo en presas cemento portland que en otras normas es calificado en general como "de bajo calor de hidratación", en base a limitaciones más restrictivas de la composición potencial, en tanto que el cemento que en el citado PCCH-64 se define como "de bajo calor de hidratación" y que por las limitaciones de este concepto responde también a tal denominación en las restantes normas, no se intenta recomendar para el mencionado empleo.

Quiere decirse que existe en ello una inconsecuencia que podria muy bien ser subsanada por eventuales pliegos particulares, y concretamente por los relativos a presas, en el sentido de prescribir para éstas el empleo de cementos de bajo calor de hidratación según el PCCH-64, sin más; o bien prescribir cementos portland que satisfagan ciertas condiciones (no una sola) respecto de la composición potencial. Estas condiciones no habrian de ser sólo relativas a $\mathrm{C}_{3} \mathrm{~S}$ (como en el vigente PCCH-64), ni a $\mathrm{C}_{3} \mathrm{~S}$ y $\mathrm{C}_{3} \mathrm{~A}$ o a $\mathrm{C}_{3} \mathrm{~A}$ y a $\mathrm{C}_{3} \mathrm{~S}+\mathrm{C}_{3} \mathrm{~A}$, ya que éstas se estipulan en todas las correspondientes normas para "cementos de moderado calor de hidratación", sino a $\mathrm{C}_{3} \mathrm{~S}$ y a $\mathrm{C}_{3} \mathrm{~A}$ (máximos) y a $\mathrm{C}_{22} \mathrm{~S}$ (mínimo). Por vía de ejemplo estos valores podrian ser: $\mathrm{C}_{3} \mathrm{~S} \leqslant 3 \overline{\mathrm{s}} \%$; $\mathrm{C}_{3} \mathrm{~A} \leqslant 7 \% ; \mathrm{C}_{2} \mathrm{~S} \geqslant 40$ por ciento.

A menos que lo que se considere recom endable para empleo en presas sea cemento portland "de moderado calor de hidratación", en cuyo caso bastará limitar en los correspondientes pliegos particulares el $\mathrm{C}_{3} \mathrm{~S}$ y el $\mathrm{C}_{3} \mathrm{~A}$ (ejemplo: $\mathrm{C}_{3} \mathrm{~S} \leqslant 50 \% ; \mathrm{C}_{3} \mathrm{~A} \leqslant$ $\leqslant 8 \%$ ) o el $\mathrm{C}_{3} \mathrm{~A}$ y la suma $\mathrm{C}_{13} \mathrm{~S}+\mathrm{C}_{3} \mathrm{~A}$ (ejemplo: $\mathrm{C}_{33} \mathrm{~A} \leqslant 8 \% ; \mathrm{C}_{3} \mathrm{~S}+\mathrm{C}_{3} \mathrm{~A} \leqslant 58 \%$ ); o bien limitar los valores máximos del calor de hidratación (ejemplo: $70 \mathrm{cal} / \mathrm{g}$ a 7 días y $80 \mathrm{cal} / \mathrm{g}$ a 28 dias).

Si se tiene en cuenta que, además (y aún antes) de los cementos portland en el caso de presas son idóneos otros cementos, por ejemplo los puzolánicos (e incluso los que en Italia se conocen con el nombre de "cementos a la puzolana"), y que en éstos no es viable el cálculo de la composición potencial -véase 2.4.1-, para garantizar en tal caso la condición de cementos de bajo (o de moderado) calor de hidratación sería preciso recurrir al segundo arbitrio: el de exigir los limites de calor de hidratación fijados para unos u otros cementos. Pero la determinación del calor de hidratación 
de los cementos puzolánicos presenta dificultades aún no bien resueltas, (20), que de momento demoran en general la inclusión de tal determinación como método oficial de ensayo dentro de las normas para cementos. Todo ello hace pensar que el problema subsiste, pese a que algunas normas (como la portuguesa para el caso de los cementos puzolánicos y la federal norteamericana para el caso de los cementos siderúrgicos) prescriben valores máximos para el calor de hidratación de esos cementos a $7 \mathrm{y}$ a 28 días.

\subsection{NUEVAS PRESCRIPCIONES POSIBLES}

Aparte de los aspectos considerados, aún cabe tomar en cuenta algunos otros en casos especiales de aplicación y empleo del cemento, bien dentro de las normas usuales (lo cual no suele ser frecuente), o bien en el marco de los pliegos particulares, lo que está más justificado. Por vía exclusiva de ejemplo se tratan a continuación algunos casos.

\subsubsection{Sobre la retracción.}

La retracción, importante desde el punto de vista de la fisuración del hormigón y de los morteros, es una variable que se puede medir, incluso a base de métodos fáciles de normalizar. De las cuarenta y cuatro normas reseñadas por el CEMBUREAU relativas a cemento portland no hay ninguna que prescriba sobre retracción. Si se prescribe, en cambio, en alguna de las relativas a cementos puzolánicos - véase 2.1 Por lo tanto, es éste un aspecto en el que, a tenor de los perfeccionamientos de los métodos de ensayo y de medida de la retracción, por una parte, y en consonancia con una posible fabricación de cementos de baja retracción o de retracción compensada y con las aplicaciones prácticas de dichos cementos, por otra, podría hacerse algo en posibles pliegos particulares para determinados empleos del cemento.

\subsubsection{Sobre adiciones.}

Las "adiciones" en el cemento portland (salvo la normal de yeso al clínker), autorizadas o no por las correspondientes normas, son causa de dificultades y origen de problemas de diversa indole, (32), (33) y (34), sobre todo si por adiciones se entiende materiales de condición inerte aunque "no nociva", que puedan ser añadidos en proporciones de cierta entidad.

De las cuarenta y cuatro normas reseñadas por el CEMBUREAU veinticinco, en treinta y tres casos, prevén el empleo de aćiciones en una u otra dosis, con uno u otro carácter o finalidad y para unos u otros tipos de cemento. Trece de estos casos las limitan a $1 \%$ como máximo, indicándose según las circunstancias que no deben ser perjudiciales o influir desfavorablemente en las propiedades y comportamiento del cemento; que no deben ser inertes; que deben ser coadyuvantes de la molturación del clínker o tratarse de materiales aceptados en virtud de una especificación oficial; etc. En otros seis casos se limitan las adiciones a $3 \%$ como máximo, indicándose según las circunstancias que deben ser reguladoras del fraguado; o incluir los retardadores normales del mismo; o poseer carácter especial; etc. Hay dos casos en que se señalan adiciones máximas de 5 y de $6 \%$ con carácter hidráulicamente activo (puzolánico) o no, o con carácter mixto, y según el tipo de cemento de que se trate.

El PCCH-64 admite la posibilidad de dar eventualmente la denominación comercial de "cemento portland" a mezclas ternarias de clinker, yeso y "adiciones no nocivas en proporción inferior a $10 \%$, con objeto de mejorar algunas de las cualida- 
des de los conglomerantes o de los morteros y hormigones con ellos fabricados, siempre que los cementos resultantes cumplan todas las condiciones químicas, físicas y mecánicas que se especifican para el portland...".

Aparte de la ambigüedad e imprecisión de lo subrayado, por falta de criterios y de métodos de comprobación, hay que señalar que, en general, una adición al cemento se acusa en la pérdida al fuego y/o en el residuo insoluble del mismo. Los valores máximos admitidos para ambos conceptos por el PCCH-64 son 4 y $3 \%$ respectivamente - véase 2.2.3--. Aparte de puzolanas, escorias siderúrgicas y cenizas volantes como materiales normales hidráulicamente activos, se añaden al cemento materiales de naturaleza caliza, arcillosa o cuarzosa. En los límites, y para poder razonar sobre ejemplos numéricos, caliza pura o sílice cuarzosa (arena) pura.

La limitación de pérdida al fuego a $4 \%$, en el caso de ser debida en exclusiva a dióxido de carbono procedente de una caliza, implica una adición aproximada de ésta de $9 \%$; la limitación del residuo insoluble a $3 \%$, en el caso de ser debida a una arena silicica implica una adición de ésta del $3 \%$. Es decir, ambas limitaciones suponen en conjunto la adición de un $12 \%$ de inertes detectables por la pérdida al fuego y/o por el residuo insoluble. Claro está que no se incluyen las adiciones (inertes o no) solubles y no volátiles, y por lo tanto indetectables por el residuo insoluble $\mathrm{y} / \mathrm{o}$ por la pérdida al fuego.

En general, una adición no hidráulica no será ni de tipo totalmente calizo ni absolutamente cuarzosa, sino de naturaleza mixta, margosa o arcillosa, con lo cual, junto a un insoluble que en la parte alicuota correspondiente a la participación de dicha adición en el cemento rara vez sobrepasaria el $3 \%$, tendría una parte soluble que tampoco se reflejaría totalmente en la pérdida al fuego. Para no sobrepasar los límites de pérdida al fuego y de residuo insoluble, ni el total de $10 \%$ de adiciones, la combinación que proporciona este máximo es: $9 \%$ de caliza (equivalente a $4 \%$ de pérdida al fuego) y $1 \%$ de insoluble. El conjunto tendría un $90 \%$ de parte soluble y un $10 \%$ de parte insoluble, es decir, una composición global intermedia entre las correspondientes a calizas margosas y a margas calizas, (18). Esto quiere decir que aún quedaría un margen de $2 \%$ para una adición totalmente insoluble del tipo de la arena, o mayor si se trata de un material parcialmente soluble y desprovisto prácticamente de pérdida al fuego, del tipo da una escoria siderúrgica, por ejemplo.

Esto viene a confirmar lo expuesto en 2.2 .3 respecto de la posibilidad de considerar en eventuales pliegos particulares una limitación más restrictiva para el residuo insoluble, aparte de la de rechazar en el caso del cemento portland las adiciones de cualquier clase $y$ en cualquier cuantia.

\section{3. conclusiones}

A la vista de cuanto antecede, $y$ con un carácter general que excluye deliberadamente una cosuística por otra parte fácil de establecer, los aspectos en los que diferentes y eventuales "Pliegos Particulares de Condiciones" para cemento portland podrían según los casos, usos y finalidades, especificar al margen del PCCH-64, y complementariamente a éste, serían los siguientes:

3.1 Finura (superficie especifica BLAINE) y/o retracción de los cementos portland $-\mathrm{y}$ más particularmente de los cementos puzolánicos, en su caso-.

3.2 Comienzo (más retrasado) del fraguado. 
3.3 Nuevas edades para ensayos de rotura, además de las del PCCH-64.

3.4 Resistencias en probetas de hormigón, además de las usuales de mortero normal.

3.5 Número de probetas de ensayo (mayor que el mínimo usual) para la determinación de las resistencias del cemento en mortero normal.

3.6 Residuo insoluble (menor que el máximo tolerado por el PCCH-64), particularmente en el caso de los cementos de categorías 350 y 450.

3.7 Proscripción de adiciones eventuales hasta $10 \%$ en cementos portland.

3.8 Limitaciones en la composición potencial de los cementos portland (sin adiciones) con miras a la durabilidad, relativas alternativamente a los siguientes conceptos:

3.8.1 $\mathrm{C}_{3} \mathrm{~S}$ máximo y/o $\mathrm{C}_{2} \mathrm{~S}$ mínimo, y $\mathrm{C}_{3} \mathrm{~A}$ máximo;

3.8.2 $\mathrm{C}_{3} \mathrm{~S}$ máximo y $2 \mathrm{C}_{3} \mathrm{~A}+\mathrm{C}_{4} \mathrm{AF}$ máximo;

3.8.3 $\mathrm{C}_{3} \mathrm{~S}+\mathrm{C}_{3} \mathrm{~A}$ máximo y $2 \mathrm{C}_{3} \mathrm{~A}+\mathrm{C}_{4} \mathrm{AF}$ máximo.

Los valores de estas limitaciones podrían y deberian ser en cada caso análogos (o iguales) a los indicados en el texto.

3.9 Condición de "cemento de bajo contenido de álcalis" según el PCCH-64, o con un límite máximo más bajo para dicho contenido.

3.10 Condición de "cemento de bajo calor de hidratación" según el PCCH-64.

3.11 Alternativamente a 3.10 , la imposición de más de una condición relativa a la composición potencial de los "cementos de moderado y/o de bajo calor de hidratación", con criterios análogos a los de 3.8 y valores semejantes (o iguales) a los indicados en el texto.

3.12 Empleo de cementos más idóneos, de tipo o clase distintos a los del portland, con o sin prescripciones complementarias a las del PCCH 64.

\section{REFERENCIAS}

1. ASTM: Standards (American Society for Testing and Materials), 1916 Race St., Philadelphia, Pa. 19103, U.S.A.

2. DIN: Deutscher Normenausschuss, Berlin W 55, Uhlandstrasse 175, República Federal de Alemania.

3. BSS: British Standard Specifications of the British Standard Institution, 2 Park St. London W 1, Inglaterra. 
4. GOST: Gosudarstvennei Komitet Soveta Ministrov po Delat Stroitelstva, Moscú, 1962, U.R.S.S.

5. CEMburead: The European Cement Association. Association Européenne du Ciment, 2, rue Saint Charles, Paris XVe, Francia.

6. CEMBUREAU: "Review of the portland cement standards in the world", 1961.

7. CEMBUREAU: "Review of standards for cements other than portland", 1958.

8. ISO: International Standardization Organization. Organisation Internationale de Normalisation. Comité Technique ISO/TC 74: Liants hydrauliques. Secrétariat: 29, avenue de Ia Brabançonne, Bruxelles 4. Bélgica. Secrétariat Général: 1 rue de Varembé. Genève. Suiza.

9. RIIEM: Réunion Internationale des Laboratoires d'Essais et des Recherches sur les Matériaux et les Constructions, 12, rue Brancion, Paris XVe, Francia.

10. PCCH-64: Pliego de Condiciones para la Recepción de Conglomerantes en las Obras de Carácter Oficial. Manuales y Normas del IETCC, Madrid, 1964.

11. Normas UNE: Instituto Nacional de Racionalización, Serrano, 150, Madrid-6.

12. Primeros Coloq̨uios de Directores y Técnicos de Fábricas de Cemento. IETCC, Madrid, 1954.

13. Segundos Coloquios de Directores y Técnicos de Fábricas de Cemento. IETCC, Madrid, 1957.

14. Terceros Coloquios de Directores y Técnicos de Fábricas de Cemento. IETCC, Madrid, 1960.

15. Cuartos Coloquios de Directores y Técnicos de Fábricas de Cemento. IETCC, Madrid, 1964.

16. J. Callesa: "Resumen y Comentarios" del Coordinador y Ponente General de los Cuartos Coloquios de Directores y Técnicos de Fábricas de Cemento. Materiales de Construcción (IETCC), núms. 118 y 119, Madrid, 1965.

17. J. Nadal y P. García de Paredes: "Empleo de los Conglomerantes Hidráulicos". Manuales y Normas del IETCC, Madrid, 1965.

18. J. Callaesa: "Cemento portland: Cálculo e Interpretación de Datos Químicos". Manuales y Normas del IETCC, Madrid, 1960.

19. J. Calleja: “Conglomerantes Hidráulicos: Fisicoquímica y Tecnologia”. Monografía, número 214 del IETCC, Madrid, 1961.

20. J. Calleja: “Apología de los Conglomerantes Puzolánicos”. Cemento y Hormigón, núm. 386, junio 1966 .

21. Instrucción HA-61 Especial para Estructuras de Hormigón Armado. Manuales y Normas del IETCC, Madrid, 1961.

22. Instrucción para el Proyecto y la Ejecución de Obras de Hormigón en Masa o Armado: Propuesta del Grupo de Trabajo. Ministerio de Obras Públicas, Madrid, 1966.

23. Normas HP 1-60 de la AEHP para Ia Fabricación de Viguetas de Hormigón Pretensado. Manuales y Normas del IETCC, Madrid, 1960.

24. J. Calleia: "Limitaciones lógicas del campo de aplicación y de la validez de resultados de los ensayos de expansión de cementos en autoclave". Trabajo en curso.

25. Y. Lacrorx: "Analyse Chimique: Interprétation des Résultats par le Calcul Statistique". Masson et Cie. Editeurs, Paris, 1962.

26. ASTM C151-64: Standard Method of Test for Autoclave Expansion of Portland Cement.

27. J. Calleja: "Influencia del contenido de yeso del cemento portland sobre la retracción de las pastas, morteros y hormigones". III Reunión Internacional sobre Reactividad de los Sólidos. Madrid, 1956. 
28. J. Calleja: "Aumento de la producción de cemento y mejora simultánea de la calidad". Materiales de Construcción (IETCC), núms. 76 a 78, 1956.

29. J. Calleja: “Mejora de la productividad en las industrias del cemento y de la construcción". Premio "Juan de la Cierva", 1958.

30. J. Calleja: "El yeso como constituyente de los conglomerantes hidráulicos". I Congreso Internacional sobre las Obras Públicas en Terrenos Yesíferos. IETCC, Madrid, 1962. Materiales de Construcción (IETCC), núm. 110, 1963.

31. J. Calleia: "Puntos de vista sobre el contenido de yeso en los cementos portland". Materiales de Construcción (IETCC), núm. 120, 1965.

32. J. Calleja: "Observaciones acerca de la dosificación de cemento en morteros y hormigones fraguados”. Informes de la Construcción (IETCC), núm. 173, pág. 101, 1965.

33. J. Calleja: "Consideraciones sobre los contenidos nominal y real de materiales hidráulicamente activos en los conglomerantes". Informes de la Construcción (IETCC), núm. 173, pág. 119, 1965.

34. J. Callfas: "Consideraciones sobre el cálculo de la composición potencial de los conglomerantes hidráulicos”. Monografía, núm. 263 del IETCC, Madrid, 1967.

35. ASTM C114-65: Standard Methods for Chemical Analysis of Hydraulic Cement.

36. ASTM C150-65: Standard Specification for Portland Cement.

37. R. H. Bogue: "The Chemistry of Portland Cement". 2nd edition. Reinhold Publishing Corporation, New York, 1955.

38. J. Calleva: "Interpretación de la composición química y potencial del cemento portland". Primer Seminario de Construcción de Carreteras, IETCC, Madrid, 1961.

39. I Congreso Internacional sobre las Obras Públicas en Terrenos Yesíferos, IETCC, Madrid, 1962.

40. J. Calleja: "El nuevo Pliego General de Condiciones para la Recepción de Conglomerantes Hidráulicos en Obras de Carácter Oficial”. Materiales de Construcción (IETCC), núm. 101, 1961.

41. J. Calleja: "Los cementos españoles ante la propuesta de un nuevo Pliego General de Condiciones". Materiales de Construcción (IETCC), núm. 101, 1961.

42. AASHO M 85-57: American Association of State Highway Officials, 917 National Press Building, Washington D. C., U.S.A.

43. ASTM C227-65: Standard Method of Test for Potential Alkali Reactivity of Cement Aggregate Combinations (Mortar Bar Method).

44. ASTM C289-66: Standard Method of Test for Potential Reactivity of Aggregates (Chemical Method)

45. ASTM C186-55: Standard Method of Test for Heat of Hydration of Portland Cement. 